\title{
Coupling Thermomechanical Processing and Alloy Design to Improve Textures in Mg-Zn-Ca Sheet Alloys
}

\author{
TRACY D. BERMAN $\mathbb{D}^{1,2}$ and JOHN E. ALLISON ${ }^{1}$ \\ 1.-Department of Materials Science and Engineering, University of \\ Michigan, 2200 Bonisteel Blvd, Gerstacker Bldg., Room 2026, Ann Arbor, MI 48109, USA. \\ 2.-e-mail: tradiasa@umich.edu
}

\begin{abstract}
The effect of $\mathrm{Ca}$ and $\mathrm{Zn}$ additions on the microstructure and texture evolution during thermomechanical processing of $\mathrm{Mg}-\mathrm{Zn}-\mathrm{Ca}$ sheet alloys was systematically investigated and quantified. Plane strain compression testing in a Gleeble thermomechanical simulator was used to physically simulate a 10pass rolling schedule, while allowing for careful control and monitoring of the processing parameters. Textures in the as-deformed ternary alloy samples demonstrate a weak maximum basal intensity and spreading in the transverse direction. Increasing the $\mathrm{Zn}$ content to $3.2 \mathrm{wt} . \%$ in the ternary alloys resulted in samples that exhibited weak textures in the as-deformed state. Importantly, static recrystallization (SRX) during post-deformation annealing of these alloys promoted a desirable annular texture, with the $c$-axis tipped from the normal direction and a lower basal texture intensity. The evolution in texture during SRX is associated with as-deformed microstructures with broad grain orientation spreads and a low degree of recrystallization.
\end{abstract}

\section{INTRODUCTION}

The pursuit for magnesium alloy sheet with good low-temperature formability is important to expand $\mathrm{Mg}$ utilization for formed products. Mg alloys which include rare earth (RE) elements have demonstrated improved formability, which is generally attributed to the "rare earth" texture, which is marked by a spreading and weakening of the basal poles along the transverse direction in the sheet. ${ }^{1-5}$ However, the cost of $\mathrm{RE}$ elements has encouraged the development of alternative solutions. Weak and spread basal textures and promising sheet formability results have also been observed in some non$\mathrm{RE}$-containing alloys, including many in the $\mathrm{Mg}-$ Zn-Ca alloy system. ${ }^{4,6-12}$ The mechanism (or more likely mechanisms) responsible for texture weakening in the $\mathrm{Mg}-\mathrm{Zn}-(\mathrm{RE}, \mathrm{Ca})$ systems remain unknown, but retarding both dynamic recovery and basal texture producing recrystallization mechanisms seem to be important. ${ }^{1,13-15}$

In conventional $\mathrm{Mg}$ sheet alloys, it is common for basal texture to be preserved during static recrystallization (SRX). ${ }^{16-21}$ The intensity of this texture

(Received November 14, 2020; accepted February 28, 2021; published online March 29, 2021) may reduce slightly, but the recrystallized grains tend to have orientation near that of their parent. In contrast, SRX can lead to more dramatic changes in texture in $\mathrm{Mg}-\mathrm{Zn}-(\mathrm{Ca}, \mathrm{RE})$ alloys. Griffiths et al. ${ }^{22}$ demonstrated the dependence of these changes on the strain path in ZEK100 (nominal composition Mg-1.3 wt.\% Zn-0.2 wt.\% Nd-0.3 wt.\% Zr). Mackenzie et al. ${ }^{17}$ observed weak non-basal textures after SRX in Mg-Zn-Ce alloys. Depending on processing, Mg-Zn-(Ca, RE) alloys may develop a texture with basal peak splitting in both the rolling and the transverse directions (RD and TD), which suggests more promising formability. ${ }^{15}$

Luo et al. ${ }^{10}$ have already explored the effects of $\mathrm{Zn}$ and $\mathrm{Ca}$ on microstructure during thermo-mechanical processing (TMP). They studied four hot-rolled $\mathrm{Mg}-\mathrm{Zn}-\mathrm{Ca}$ alloy sheets, ranging in composition from Mg-1.95Zn-0.75Ca to Mg-0.73Zn-0.12 Ca, and found that all four of the Mg-Zn-Ca alloys demonstrated a reduced basal texture intensity after annealing. The two alloys with $\sim 2$ wt.\% $\mathrm{Zn}$ showed basal peak splitting along the TD direction and similar peak intensities, despite one of these alloys containing 0.3 wt.\% more $\mathrm{Ca}$. The alloys with $\sim 0.75$ wt.\% $\mathrm{Zn}$ both showed suggestions of a quad-texture (basal peak splitting in both the RD and the TD), but once again 
comparable maximum texture intensities regardless of Ca content. Given that the processing between the high and low $\mathrm{Zn}$ alloys was also different (the high Zn alloys were subjected to fewer passes and less thickness reduction due to edge cracking), it is unknown whether the quad-texture was a result of the reduced $\mathrm{Zn}$ content, the processing, or a combination of these factors. In addition, only the annealed texture was reported, so the texture evolution during the annealing treatment is also unknown.

Although considerable work has been carried out towards the development of formable magnesium alloy sheet, it is often difficult to draw firm conclusions from the literature. Both alloying and thermomechanical processing (TMP) conditions affect the texture evolution; however, it is common to not report key TMP variables used in the rolling process, in particular, the feed-through rate of the sheet, which, in addition to the rolling reduction, determines the strain rate. Monitoring the temperature of the sheets during the rolling process is difficult. Pre-rolling annealing treatments and roll temperatures are generally described, but the temperature of the sheet will fluctuate when passed between steps. As pointed out by Imandoust et al., ${ }^{13}$ obtaining the desired texture will require knowledge of the interactions between all the alloying elements and optimizing processing parameters for that particular alloy. Therefore, it is important to control and record those processing variables to properly establish the processing-microstructure relationships.

The purpose of this study is to systematically quantify the role of TMP and alloying on the texture evolution and microstructure of Mg-Ca binary and Mg-Zn-Ca ternary alloys in both the as-deformed condition and after annealing. A thermomechanical processing simulator was used to physically simulate the rolling process, allowing for careful control of conditions so that processing paths can more accurately be coupled to the resulting microstructure. All alloys were prepared using the same processing schedule. This work is part of the Department of Energy Low-Cost Magnesium Sheet Component Development and Demonstration Project. More details on this United States Council for Automotive Research project can be found in the paper by Luo et al. ${ }^{23}$

\section{EXPERIMENTAL}

Cast ingots with dimensions of approximately 80 $\mathrm{mm} \times 80 \mathrm{~mm} \times 20 \mathrm{~mm}$ were received from the University of Florida. A summary of the compositions studied is shown in Table I. The binary ingots were solution treated for $24 \mathrm{~h}$ at $500^{\circ} \mathrm{C}$, while the ternary ingots were solution treated for $24 \mathrm{~h}$ at $350^{\circ} \mathrm{C}$. Plane strain compression samples with dimensions of $20 \mathrm{~mm} \times 15 \mathrm{~mm} \times 10 \mathrm{~mm}$ were extracted from the center regions of the ingots. TMP
Table I. Alloy designation and composition as measured using optical emission spectroscopy

\begin{tabular}{|c|c|c|}
\hline Alloy name & Zn content (wt.\%) & Ca content (wt.\%) \\
\hline Unalloyed & 0 & 0 \\
\hline X0 & 0 & 0.1 \\
\hline $\mathrm{X} 1$ & 0 & 0.3 \\
\hline ZX21 & 1.9 & 0.3 \\
\hline ZX30 & 3.2 & 0.1 \\
\hline ZX31 & 3.2 & 0.3 \\
\hline
\end{tabular}

simulation was conducted using a Gleeble Model 3500 thermo-mechanical simulator (Dynamic Systems, Poestenkill, NY, USA), with two $k$-type thermocouples spot-welded to the sample surface (one at mid-height and a second at quarter-height). The thermomechanical processing schedule used consisted of 10 compressive hits of equal strain (0.2), resulting in a thickness reduction from $10 \mathrm{~mm}$ to approximately $1.8 \mathrm{~mm}$. A strain rate of $0.5 \mathrm{~s}^{-1}$ was used. All the samples were heated to $350^{\circ} \mathrm{C}$ at a rate of $5^{\circ} \mathrm{C} / \mathrm{s}$ and then held at $350^{\circ} \mathrm{C}$ for $10 \mathrm{~min}$ before the first compressive hit. The temperature was held at that constant temperature during the entire processing routine, including 10-min thermal soaks between passes. After the final hit, all specimens were air-quenched within the Gleeble system for 30 s. The deformed specimens were cut in half. One portion of each sample was annealed for $30 \mathrm{~min}$ at $350^{\circ} \mathrm{C}$ in a small box furnace followed by a waterquench. An additional ZX30 sample was tested, the only difference in processing being that the duration of the final annealing treatment was $10 \mathrm{~min}$.

Optical microscopy and electron backscatter diffraction (EBSD) mapping were used to characterize the as-deformed and annealed materials. The samples were mounted such that the compression direction was normal to the grinding surface. Polishing was conducted using diamond paste and an oil-based lubricant. For optical microscopy, the samples were etched in a solution of $10 \mathrm{~mL}$ water, $10 \mathrm{~mL}$ acetic acid, $4.3 \mathrm{~g}$ of picric acid (crystals), and $70 \mathrm{~mL}$ of ethanol for approximately $3-5 \mathrm{~s}$. The final preparation step before EBSD was etching for approximately 5 seconds in a solution of $60 \mathrm{~mL}$ ethanol, $20 \mathrm{~mL}$ water, $15 \mathrm{~mL}$ glacial acetic acid, and $5 \mathrm{~mL}$ of nitric acid.

EBSD was conducted using a Tescan Mira3 electron microscope operated at $30 \mathrm{k} \mathrm{eV}$ with a beam intensity setting of 20 . Two sets of scans were collected for each alloy specimen. An $800-\mu \mathrm{m} \times 800$ $\mu \mathrm{m}$ scan with a step size of $1.2 \mu \mathrm{m}$ was used to study the grain size and morphology, and was also used to calculate grain orientation spread (GOS). Larger scans were used to determine the crystallographic texture. These scans were collected using a step size of $3 \mu \mathrm{m}$, and represent an area of at least $4 \mathrm{~mm}^{2}$ for each specimen. A single scan was collected on the pure $\mathrm{Mg}$ specimens, covering a $4-\mathrm{mm} \times 1-\mathrm{mm}$ area 
with a step size of $1.5 \mu \mathrm{m}$. MTEX $^{24}$ was used to generate the orientation distribution functions and inverse pole figure (IPF) maps for each condition. OIM Analysis was used to generate the GOS maps. A $5^{\circ}$ misorientation tolerance was used to define a grain. Data points with a confidence index less than 0.1 were excluded from analysis; these points are shown as white and black pixels in the IPF and GOS maps, respectively. In the case of the more soluterich alloys, these non-indexed points were often observed to be a result of secondary-phase particles. An example of that is in alloy X1 in Figs. 2 and 3. It should be noted that the non-indexed pixels can also result from defocusing of already weak patterns in deformed materials due to the high tilt required for EBSD imaging, such as seen in Fig. 3a for ZX30 and especially ZX31, and should not be confused with those points due to secondary phase particles.

\section{RESULTS}

The Gleeble true stress-true strain responses for all six alloys are presented in Fig. 1a. Although there is some scatter between the tests, the strain achieved at each pass and the total strain for all samples is relatively consistent. As expected, the ternary alloys exhibit a higher stress during compression than the unalloyed $\mathrm{Mg}$ and binary alloys, as $\mathrm{Zn}$ provides both solid solution strengthening and grain refinement. ${ }^{25}$ The binary alloys show comparable behavior to the unalloyed $\mathrm{Mg}$, which is not unexpected given their low Ca content and incomplete solution treatment. ${ }^{26}$ It should be noted that the binary alloys also had a larger initial grain size than the unalloyed $\mathrm{Mg}$, which was used in the ascast condition.

The temperature profiles of all specimens overlay each other in Fig. 1b, demonstrating that all the samples were subjected to the same thermal environment. The spikes in the temperature are coincident with the compressive hits, after which the Gleeble quickly returned each sample to the set temperature of $350^{\circ} \mathrm{C}$. The cooling rate during the post-deformation air-quench was measured to be approximately $7^{\circ} \mathrm{C} / \mathrm{s}$. A schematic comparing the sample orientation convention used for plane strain compression testing relative to rolling is shown in Fig. 1c. The normal direction (ND) is parallel to the compressive force $(\mathrm{F})$ from either the rollers or the anvils, and the material is free to elongate in the $\mathrm{RD}$. The TD is coming out of the page in the illustration.

\section{Microstructure}

After deformation, the unalloyed $\mathrm{Mg}$ and binary alloys exhibited an inhomogeneous microstructure consisting of bands of finer grains surrounded by larger grains, as illustrated by the optical micrograph of the X0 alloy in Fig. 2a. In contrast, the ternary alloys have a finer and more consistent grain size through the reduced section, with a mean (a)

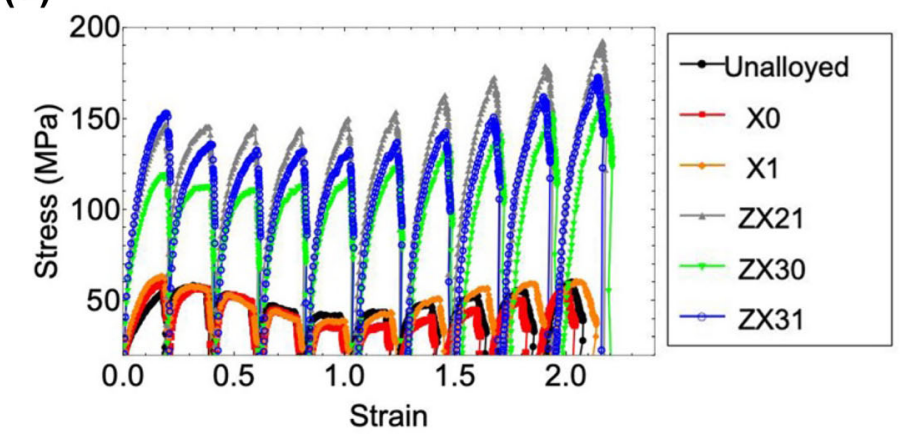

(c)

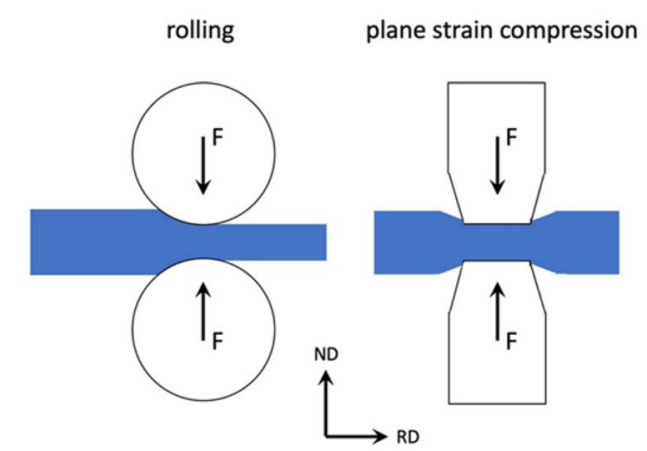

(b)

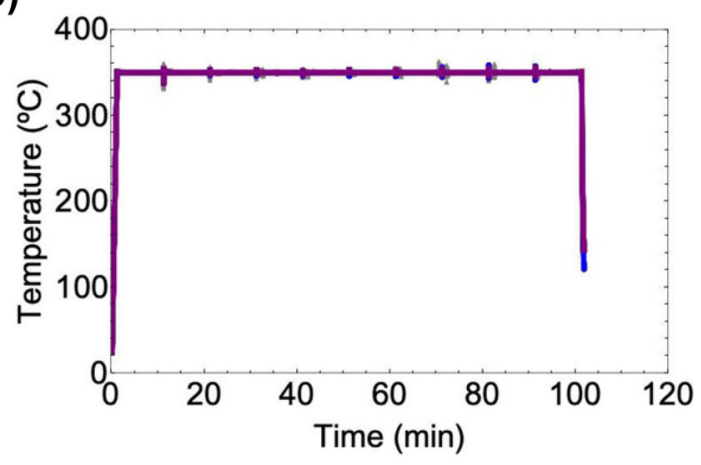



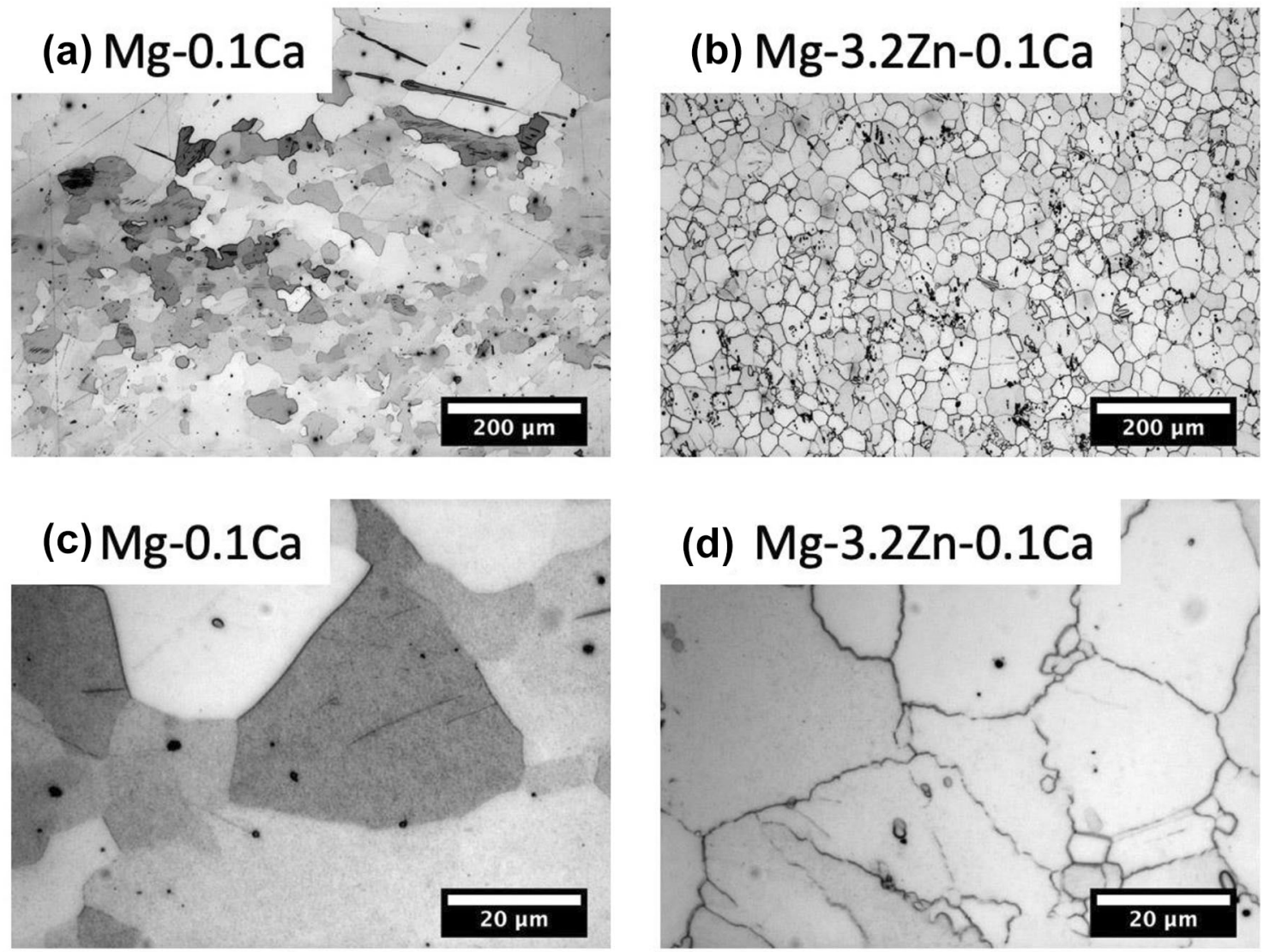

Fig. 2. Optical micrographs of $(a, c)$ deformed Mg-0.1Ca binary, and (b, d) deformed Mg-3Zn-0.1Ca ternary alloy. The rolling direction is vertical.

grain diameter of approximately $20 \mu \mathrm{m}$, as can be seen in the ZX30 alloy in Fig. 2b. As processing for all the alloys was fixed, the grain refinement and more homogenous as-deformed microstructure in the ZX30 alloy is attributed to the addition of 3.2 wt.\% $\mathrm{Zn}$ to $\mathrm{Mg}-0.1 \mathrm{Ca}$.

Higher magnification microscopy reveals a second difference in the deformed condition: all three ternary alloys exhibited serrated grain boundaries, evidence of grain boundary bulging, and sub-micron grains decorating the boundaries of some of the larger grains (Fig. 2d). These features are considered characteristics of discontinuous dynamic recrystallization (DDRX). ${ }^{18}$ The grain boundary structures in the unalloyed $\mathrm{Mg}$ and binary alloys are fairly straight, even in the finer-grained regions highlighted in Fig. 2c.

EBSD IPF maps also highlight the differences in microstructure between the alloys with and without Zn (Fig. 3). Some twins are observed in the largergrained unalloyed $\mathrm{Mg}$ and binary alloy samples, while very few are observed in the finer-grained ternary alloys. The post-deformation annealing treatment of $30 \mathrm{~min}$ at $350^{\circ} \mathrm{C}$ resulted in grain growth in the unalloyed $\mathrm{Mg}$ and binary alloys. Unlike in the unalloyed $\mathrm{Mg}$ and binary materials, the annealing treatment did not lead to substantial grain growth in the Zn-containing alloys. No evolution in grain size is seen in the solute-rich ZX31 alloy. The grain size increases slightly in the ZX30 alloy (which contains the lowest wt.\% $\mathrm{Ca}$ of the ternaries) from $20 \mu \mathrm{m}$ to just under $30 \mu \mathrm{m}$. Based on the $800-\mu \mathrm{m} \times 800-\mu \mathrm{m}$ EBSD maps, which contain over 700 grains each, the grain diameter in ZX21 appears to decrease from $25 \mu \mathrm{m}$ in the deformed condition to $12 \mu \mathrm{m}$ in the annealed condition, suggesting that recrystallized grains consumed the larger, deformed parent grains.

EBSD GOS maps (Fig. 4) were used to characterize the extent of recrystallization before and after annealing. Figure 4a illustrates differing amounts of recrystallization (RX) in the as-deformed state. Given the inhomogeneity in the unalloyed $\mathrm{Mg}$ and binary materials, the maps shown for the unalloyed $\mathrm{Mg}$ and binary alloys in Figs. 3 and 4 should not be interpreted as completely representative of the microstructure, but it is clear that the bulk of these materials are in a deformed, unrecrystallized state. More quantitative information can be drawn from the more homogeneous and finer-grained ternary alloys. GOS maps of the ZX21 sample showed bands of grains with a misorientation of $1^{\circ}$ or less perpendicular to the RD. Using $1^{\circ}$ as the cutoff between deformed and recrystallized grains, ${ }^{27,28}$ the ZX21 sample is $\sim 40 \%$ recrystallized. The two alloys with 3.2 wt. $\% \mathrm{Zn}$ are less than $1 \% \mathrm{RX}$ after 10 hits.

The post-deformation annealing treatment did not lead to complete SRX in the unalloyed $\mathrm{Mg}$ and binary 
(a)
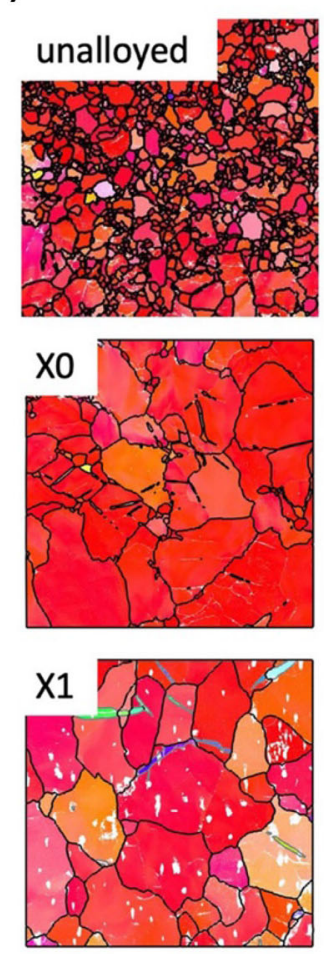

(b)
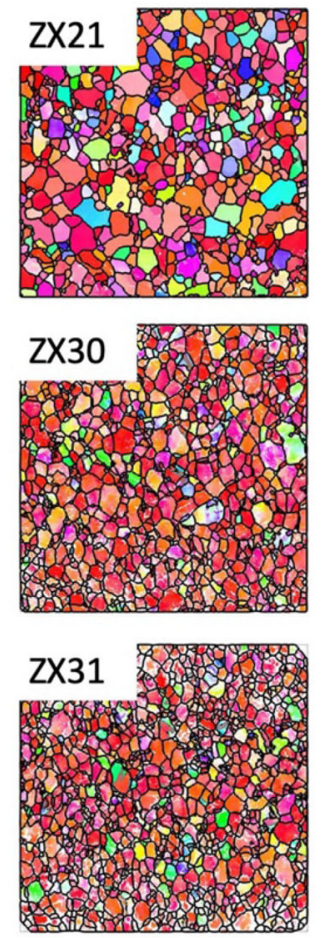
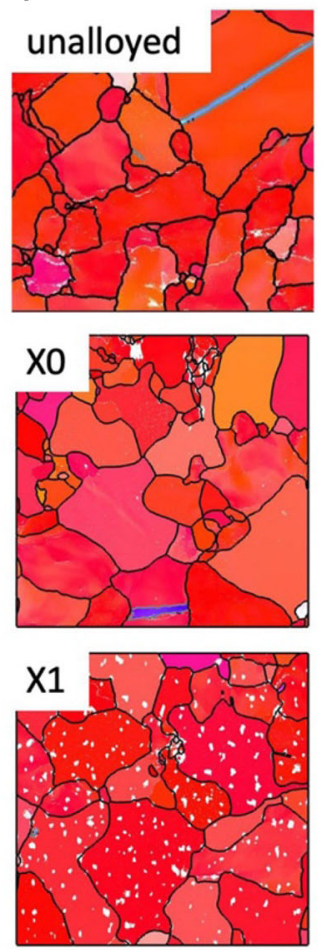

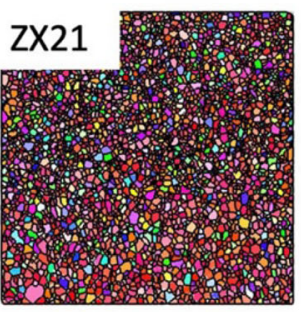

$400 \mu \mathrm{m}$
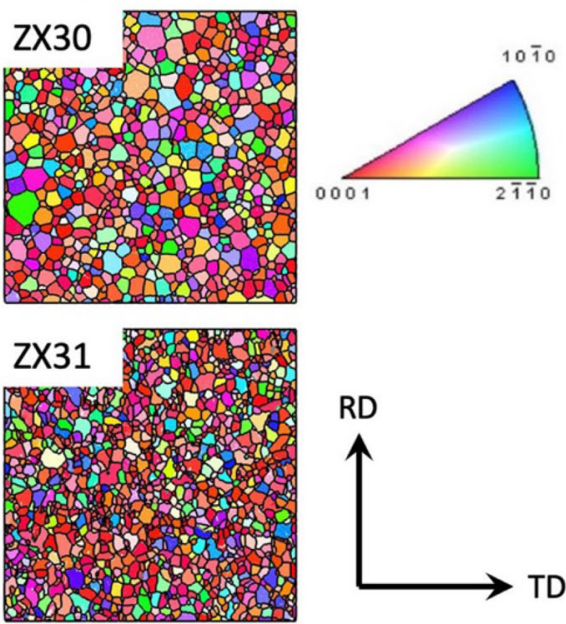

Fig. 3. EBSD IPF maps comparing the microstructure and texture of the alloys in (a) as-deformed, and (b) annealed conditions. Note that white pixels may be due to second phase particles (e.g., alloy X1) or beam defocusing at the top and bottom in highly deformed samples (e.g., ZX30 and ZX31 in (a)). (For interpretation of the figure legend, the reader is referred to the web version of this article).

(a)
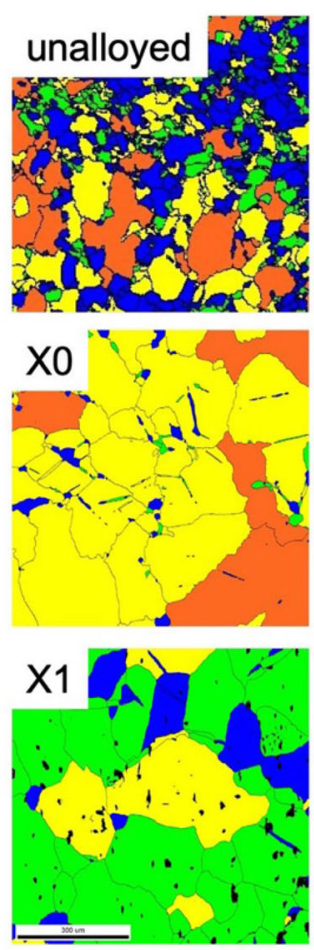

(b)
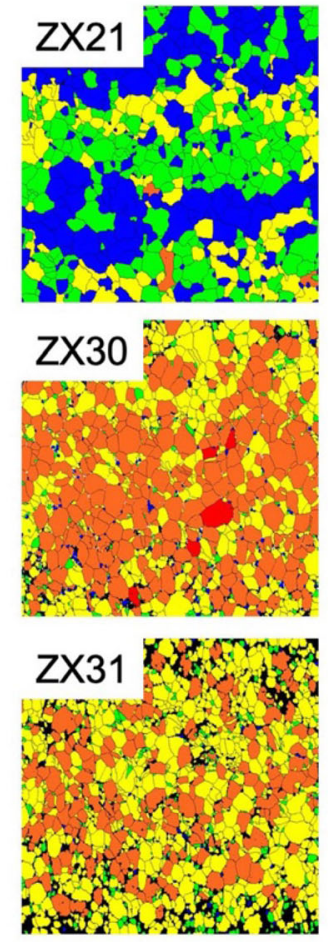
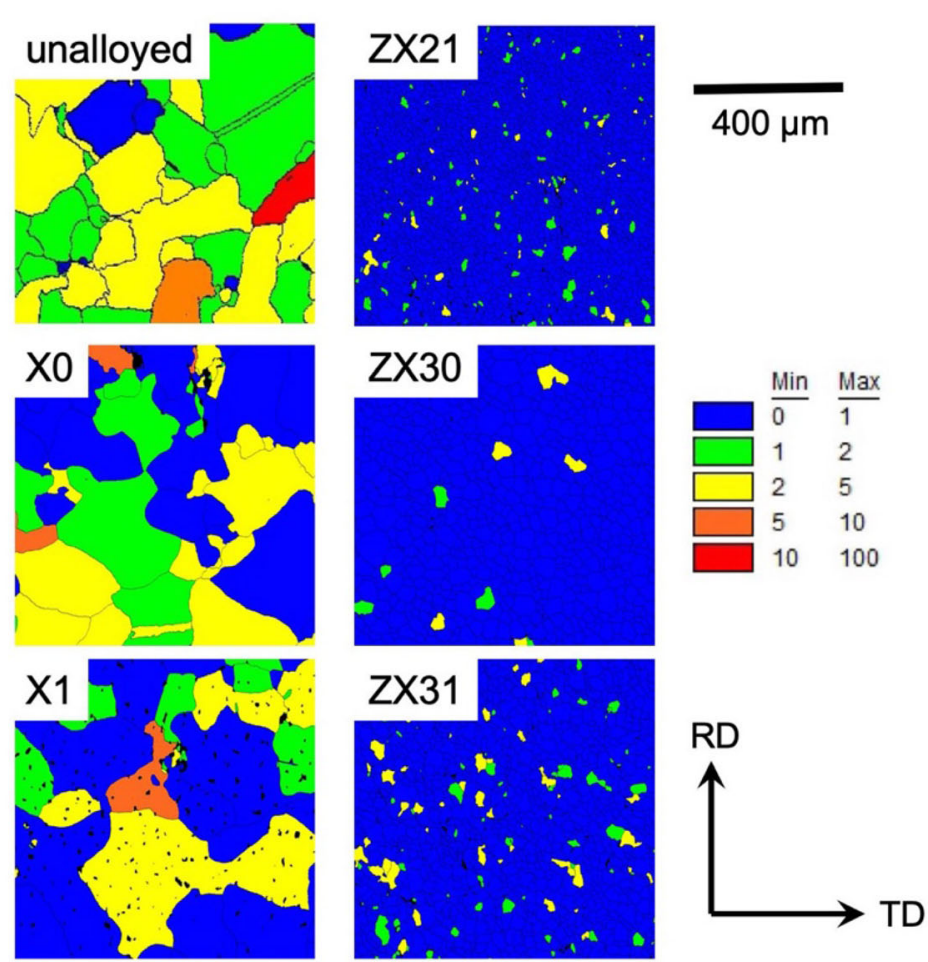

Fig. 4. EBSD GOS maps of the samples in (a) as-deformed, and (b) annealed conditions. All maps cover an area of $800 \mu \mathrm{m} \times 800 \mu \mathrm{m}$. Nonindexed pixels are shown in black. (For interpretation of the figure legend, the reader is referred to the web version of this article). 
materials (Fig. 4b). Histograms of the GOS distribution in the six alloys (Fig. 5) show little evolution in grain misorientation in the unalloyed $\mathrm{Mg}$, and only a slight shift to lower internal misorientations in the binary alloys. The final annealing treatment resulted in more extensive SRX in the three ternary alloys. The faster SRX kinetics in the ternary alloys is consistent with their finer as-deformed grain size. ${ }^{28}$ The microstructure of all three of these alloys after annealing consists primarily of equiaxed grains with low internal misorientation (Figs. $3 \mathrm{~b}$ and $4 \mathrm{~b}$ ). The GOS distribution is comparable for all three of the ternary alloys after annealing (Fig. 5). In the asdeformed condition, the $3.2 \mathrm{wt}$.\% $\mathrm{Zn}$ alloys contain a larger number fraction of grains with a high internal misorientation. The distribution of GOS values in ZX30 and ZX31 is centered a few degrees higher, and is broader than that measured in the ZX21 sample.

\section{Texture}

The as-deformed and post-annealing textures in the unalloyed $\mathrm{Mg}$ and binary alloys and the ternary alloys are quite different, and therefore it should be noted that different scale bars are used for the two sets of materials in Fig. 6. The unalloyed $\mathrm{Mg}$ and binary alloys all exhibit a strong basal texture, with a maximum intensity greater than 12 multiples of random density (MRD), in the deformed condition (Fig. 6a). Annealing for $30 \mathrm{~min}$ did not lead to any appreciable change of texture in these unalloyed $\mathrm{Mg}$ and binary alloys. Slight inclinations of the peak of the pole figures from the center (ND) are a consequence of variations in specimen mounting.

The ternary alloys all exhibited comparatively weak textures in the deformed state, with maximum basal pole figure intensities in the range of 3-5 MRD (Fig. 6b). The basal poles in these alloys are slightly spread in the transverse direction. In ZX21, the texture was largely unchanged by annealing. In the 3.2 wt.\% $\mathrm{Zn}-\mathrm{Ca}$ alloys, the final annealing treatment led to a significant change in texture, as shown in Fig. 6b (annealed). During static recrystallization, the $c$-axis of the grains tilted down, away from the sample normal, resulting in an annulus around the basal pole and a decrease in the maximum basal pole figure intensity to $\sim 2 \mathrm{MRD}$.
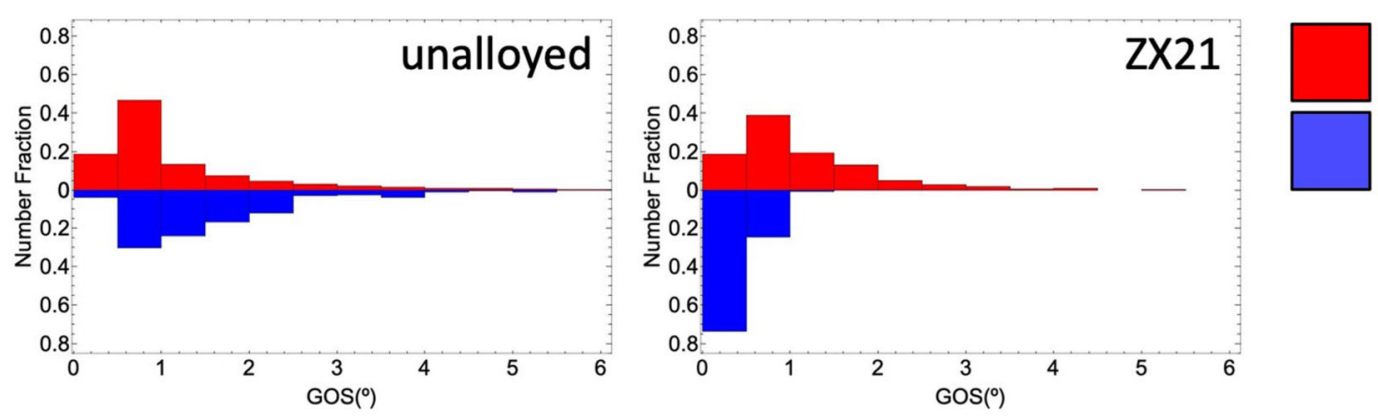

as-deformed after annealing
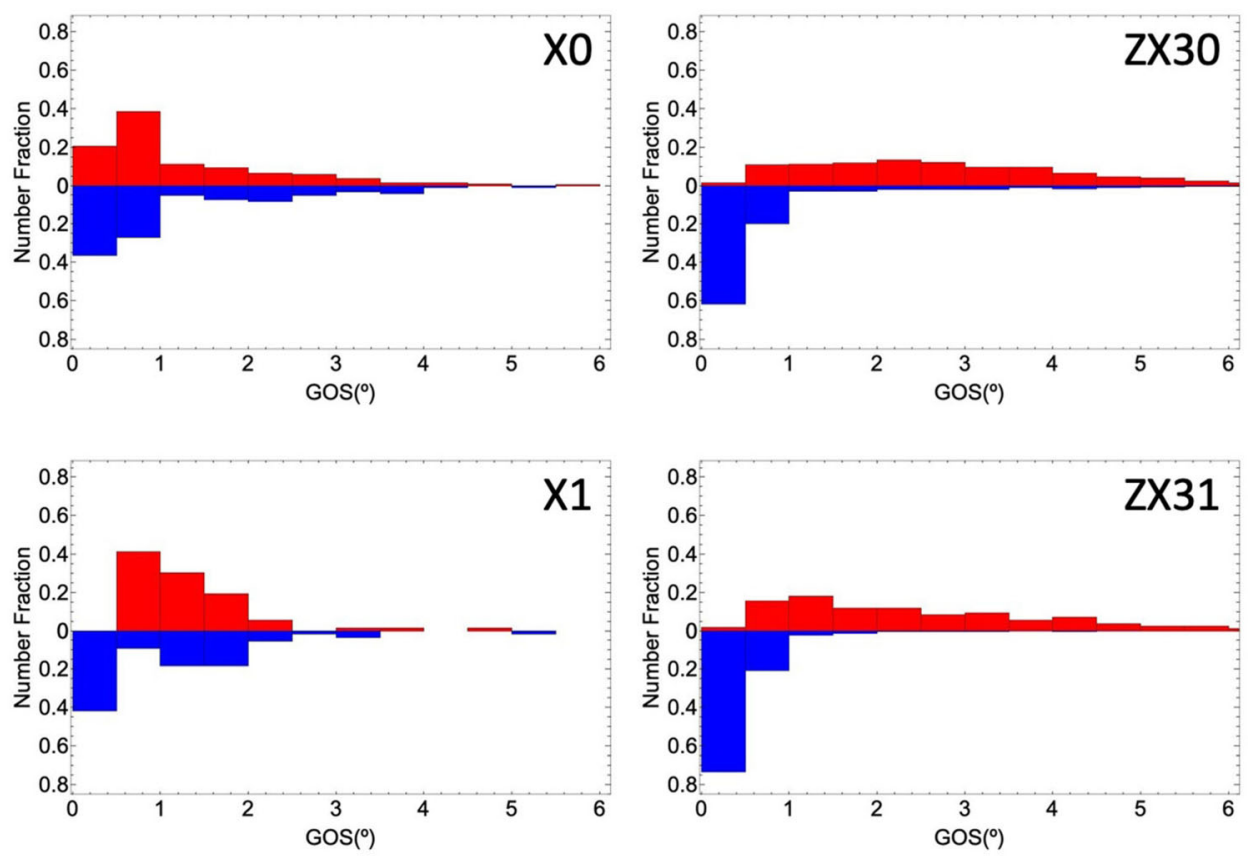

Fig. 5. Histograms comparing the evolution of GOS after annealing in the six alloys. 

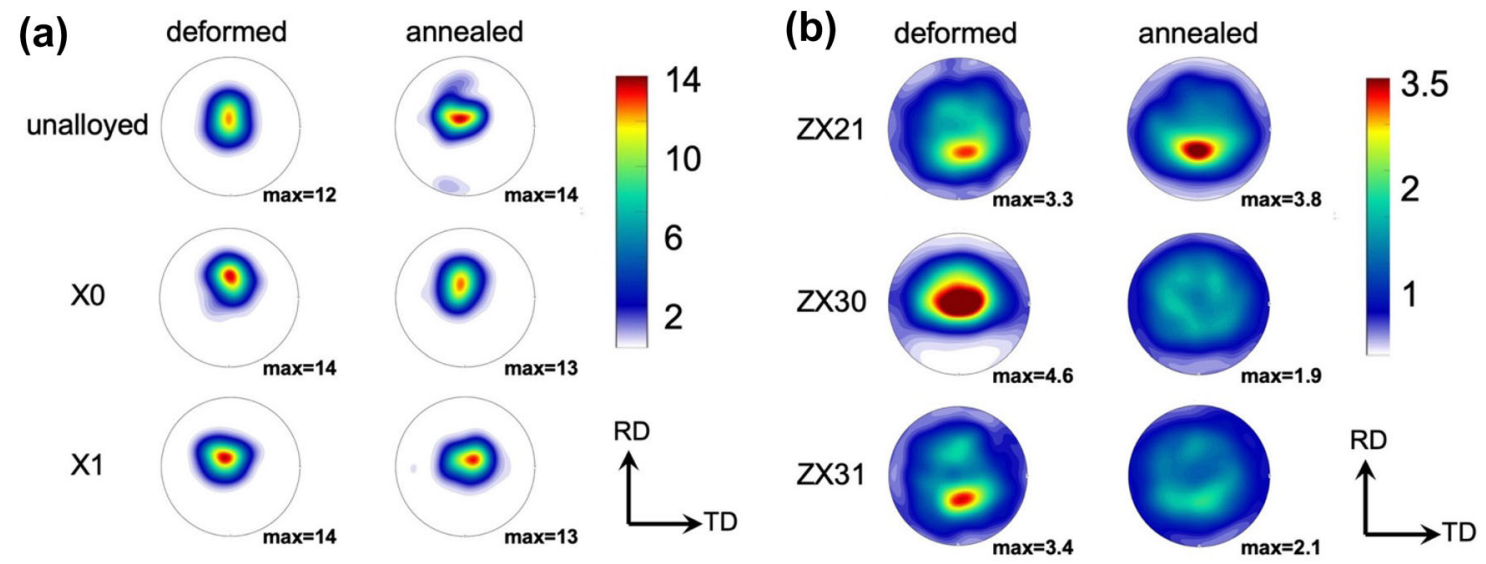

Fig. 6. Basal (0001) pole figures of (a) unalloyed Mg and Mg-Ca binary alloys, and (b) Mg-Zn-Ca ternary alloys in the as-deformed and annealed conditions. Note the substantial difference in pole figure intensity in (a) compared to (b). (For interpretation of the figure legend, the reader is referred to the web version of this article).
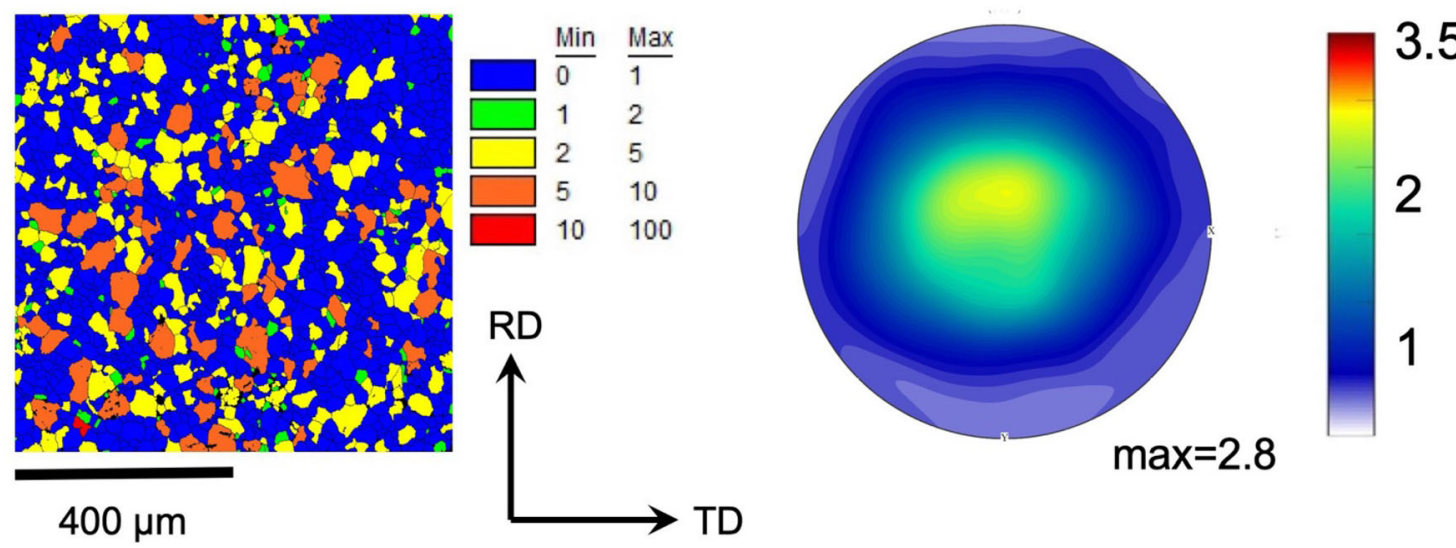

Fig. 7. EBSD GOS map and texture in $\mathrm{ZX} 30$ after annealing at $350^{\circ} \mathrm{C}$ for $10 \mathrm{~min}$. (For interpretation of the figure legend, the reader is referred to the web version of this article).

The ZX30 alloy showed the most dramatic change in texture during annealing. In order to further explore the evolution, an additional specimen was annealed for $10 \mathrm{~min}$ at $350^{\circ} \mathrm{C}$. Annealing for this shorter duration resulted in incomplete SRX: approximately two-thirds of the grains have a grain orientation spread less than $1^{\circ}$ (Fig. 7). At this intermediate recrystallization step, the intensity of the basal texture has reduced, but retains its basal character. The non-basal, annular texture shown in Fig. $6 \mathrm{~b}$ is thus not produced until the later stages of SRX.

\section{DISCUSSION}

The ternary alloys exhibited much different microstructure and texture behavior during TMP and annealing than the $\mathrm{Zn}$-free alloys. Relatively weak basal textures were produced in all three of the ternary alloys. This is consistent with existing literature that demonstrates that alloying with $\mathrm{Zn}+$ ( $\mathrm{RE}, \mathrm{Ca}$ ) can prevent the development of strong basal and RD-split basal textures typically seen in AZ31. 6,10,11,15,29 The addition of $\mathrm{Ca}$ alone did not change the texture evolution from that observed in unalloyed $\mathrm{Mg}$ in this study, although Lee et al. ${ }^{30}$ did observe basal texture reduction during SRX in the same binary alloys. The $\mathrm{Zn}$ content had a much stronger effect on the texture evolution than the $\mathrm{Ca}$ content. The behavior of ZX30 and ZX31 are quite similar, despite the higher Ca content in ZX31. In contrast, ZX21 and ZX31, which vary in composition by $\sim 1 \mathrm{wt} . \% \mathrm{Zn}$, had quite different final textures.

The texture in the as-deformed state in ZX21 and ZX31 is very comparable, both in the maximum intensity and in the distribution. In this state, ZX21 has a significantly higher fraction of RX grains than does ZX31 and, as a consequence, has a narrower GOS distribution. The difference in texture between 
these two alloys arises during the final recrystallization annealing treatment. The increased $\mathrm{Zn}$ content affects RX texture more strongly than the deformation texture. This may be a consequence of $\mathrm{Zn}$ in solution, $\mathrm{Zn}$ segregation at grain boundaries, or Zn-enriched second-phase particles.

Evidence of DDRX was observed in the microstructures of all three ternary alloys. DDRX results when local grain boundary bulging leads to a decrease in dislocation density, acting as a nuclei for recrystallized grains that can consume adjacent deformed grains. ${ }^{18}$ This mechanism is not associated in a significant change in texture; however, the alloys which exhibited DDRX were also the alloys with a significantly weaker texture after 10 deformation passes. Reduced mobility of high-angle grain boundaries due to solute drag may have arrested DDRX and allowed for the higher grain misorientations observed in ZX30 and ZX31 GOS maps.

Multiple mechanisms contribute to the texture in the as-deformed state. One contribution is the texture that results from deformation itself. Alloying with $\mathrm{Zn}+\mathrm{Ca}$ has been demonstrated to promote non-basal slip activity, ${ }^{31}$ and therefore weaker deformation textures are expected in the ternary alloys. Texture evolution resulting from the DRX can also affect the texture in the as-deformed state. In addition, SRX that occurs during the thermal soaks between passes can also contribute to texture evolution. It is difficult to determine the relative contribution of each of these mechanisms in ex situ studies such as used in the current investigation, although computational simulations may be used to decouple them in the future.

SRX was responsible for a dramatic change in texture in the $3.2 \mathrm{wt} . \% \mathrm{Zn}$ alloys during the final 30min annealing treatment, and it is likely that SRX also affects the texture during the thermal soak between compressive passes. The duration of the thermal soak between passes was $10 \mathrm{~min}$. After 10 compressive hits, SRX was not complete after 10 min at the same temperature, so deformationinduced misorientation in the ZX30 alloy would have been able to accumulate in grains from one pass to the next. This is consistent with the broad grain orientation spread distributions measured in ZX30 (and ZX31) at the conclusion of the 10 passes.

It is important to note that only the alloys with microstructures consisting of a large fraction of highly misoriented grains underwent a change in texture during annealing. Retardation of recrystallization kinetics provides for an accumulation of internal grain misorientation during the multi-step deformation process, which allows for more extensive SRX in the final annealing treatment. Bohlen et al. ${ }^{11}$ tracked the texture evolution during static recrystallization at $400^{\circ} \mathrm{C}$ in hot-rolled $\mathrm{Mg}-0.91$ wt.\% Zn-0.52 wt.\% Ca alloy, and also observed texture reduction, which they attributed to more randomly oriented $\mathrm{RX}$ grains consuming more strongly textured deformed grains. This is consistent with the observations in the current study, in particular that the samples that underwent the most SRX also exhibited the largest texture reduction. Bohlen et al, associated the randomly nucleated grains with twins in band-like structures; however, those features that were not observed here.

The fully recrystallized $\mathrm{Mg}-3.2 \mathrm{Zn}-\mathrm{Ca}$ alloys both exhibit an annular structure in the basal pole figure, where a very low fraction of grains have their $c$-axis aligned with the ND. Unlike the traditional RE textures, these fully RX alloys do not have a broader spread in the TD or distinct peak splitting in either the RD or TD. The TD-split texture has been associated with twinning. . $^{8,14}$ Very limited twinning was observed in the ternary alloys used in this study, which is consistent with the lack of TDsplit peaks. Annular basal textures similar to that observed in this study were reported in recrystallized $\mathrm{Mg}-0.3 \mathrm{Zn}-0.1 \mathrm{Ca}$ alloy by Zeng et al. ${ }^{32}$. They also found that this texture was not associated with twinning or shear bands. It is interesting to note that Zeng at al. achieved these textures after annealing cold-rolled materials, while the current investigation has arrived at this texture after annealing material deformed at $350^{\circ} \mathrm{C}$. With the annular texture, inclination of the $c$-axis should allow for easier activation of basal slip during through-thickness deformation, and the symmetry of this texture around the ND is expected to result in more isotropic behavior within the plane of the sheet than seen in the traditional RE textures.

An increased $\mathrm{Zn}$ addition seems to retard recrystallization during processing. The deformed ZX21 specimen had a significant fraction of low misorientation grains in the as-deformed state, while the 3.2 wt.\% $\mathrm{Zn}$ alloys had very few recrystallized grains. The TMP schedule used consisted of 10 compressive hits, separated by a 10-min thermal soak, so postmortem studies after the complete 10-pass process cannot provide information on relative contributions of static and dynamic recrystallization in the as-deformed structures. However, it was shown that, for all the alloys studied, DRX grains do not occupy a large fraction of the as-deformed microstructure after 10 passes. This work did not include any $\mathrm{Mg}-\mathrm{Zn}$ binaries, but the literature has not demonstrated a reduction in basal texture intensity during annealing with $\mathrm{Zn}$ as the only solute. $^{6,30}$ The retarded kinetics may be a result of co-segregation of $\mathrm{Zn}$ and $\mathrm{Ca}$ atoms to the grain boundaries. It has been suggested that this cosegregation alters the grain boundary energies and mobilities and limits the growth of basal grains. ${ }^{32}$ Future work is needed to explore the mechanisms responsible, but the findings of this study are consistent with conclusions that it is important to retard recrystallization, and that alloying with both $\mathrm{Zn}$ and $\mathrm{Ca}$ is an effective method for doing so.

Secondary particles are one possible source of texture reduction in the ternary alloys that this work did not explore. It has been demonstrated that 
coarse, intermetallic particles can promote RE-like textures in magnesium alloys that do not contain both $\mathrm{Zn}$ and $\mathrm{RE}$ or Ca solutes. ${ }^{27}$ Large particles can promote texture reduction through the mechanism of particle-stimulated nucleation (PSN). Large particles can also promote strain localization. Robson et al. ${ }^{33}$ found that the nucleation and growth of DRX grains in the mantle region of deformed grains affected the texture more strongly than PSN. Miller et al. $^{34}$ demonstrated that coarse intermetallic particles promoted an increased GOS and a more diffuse deformation texture. Luo et al. ${ }^{10}$ have explored the effects of $\mathrm{Zn}$ and Ca concentration on the volume fraction and size of the second phase particles, and did not find an association between the particles and texture reduction. Although the distribution of secondary particles was not quantitatively analyzed in the current investigation, it was observed that the ZX30 alloy, which had a very low volume fraction of intermetallic particles after solution treatment, achieved a weaker final texture than the alloys with a higher $\mathrm{Ca}$ content which contained a higher volume fraction of intermetallic particles.

Improvements in the formability of magnesium sheet alloys, has, at least in part, been associated with the development of weak and spread basal textures. In this work, we have systematically demonstrated that these desirable textures can be produced by post-deformation annealing in selected ternary alloys of $\mathrm{Mg}-\mathrm{Zn}-\mathrm{Ca}$. It is important to note that processing, not just alloying, plays a critical role in this microstructure and texture development. The 10-pass schedule used in this work was developed based on the authors' previous work on ZX30, ${ }^{12}$ so it is not surprising that the ZX30 alloy demonstrated the weakest basal texture intensity after annealing. Optimization of the TMP schedule, for example by changing the strain per pass, the number of passes, the temperature during deformation and/or annealing, the strain rate, etc. may yield equally spread basal textures in ZX21 and additional Mg-Zn-Ca alloys. Conversely, it has been demonstrated that stronger basal textures can occur during processing of ZX30 if the strain rate is either too low or too high. ${ }^{12}$ Optimizing texture and microstructure (and therefore mechanical properties and formability) will require iteration between alloying and processing, but the $\mathrm{Mg}-\mathrm{Zn}-\mathrm{Ca}$ alloy system provides an encouraging path for the development of formable magnesium alloys that do not contain costly RE elements.

\section{CONCLUSION}

This study systematically investigated the effect of alloying on texture and microstructure evolution using a known, fixed TMP schedule. Desirablespread basal textures with a low texture intensity were produced in $\mathrm{Mg}-\mathrm{Zn}-\mathrm{Ca}$ sheet alloys through a combination of a 10-pass deformation schedule and a final recrystallization annealing treatment. The critical importance of the recrystallization that occurs during the final annealing step for producing the desired texture has been confirmed for the Mg$\mathrm{Zn}-\mathrm{Ca}$ alloys with $\mathrm{Zn}$ contents of 3.2 wt.\%. For the selected processing conditions, the $\mathrm{Zn}$ content strongly affected the texture in the as-deformed and annealed conditions. The texture and microstructure were insensitive to variations in $\mathrm{Ca}$ content between 0.1 to 0.3 wt.\%. All three ternary Mg-Zn-Ca alloys showed a significantly reduced basal texture intensity in the as-deformed condition ( $\max \sim 4 \mathrm{MRD}$ ) compared to the unalloyed $\mathrm{Mg}$ and Mg-Ca binaries ( $\max >12 \mathrm{MRD}$ ). Microstructural signatures of discontinuous dynamic recrystallization, such as grain boundary bulging, were only present in the materials with weak textures in the as-deformed condition. Annealing for $30 \mathrm{~min}$ at $350^{\circ} \mathrm{C}$ did not alter the strong texture in the unalloyed $\mathrm{Mg}$ and binary alloys, nor did SRX appreciably change the as-deformed texture in the ZX21 alloy. Significant basal texture evolution was observed during SRX in the ZX30 and ZX31 alloys. The final weak texture of these two alloys exhibited a desirable annular structure, with the $c$-axis tipped from the normal direction. This texture has not previously been reported in hot-deformed $\mathrm{Mg}-\mathrm{Zn}-\mathrm{Ca}$ and, unlike the TD-split texture, is not associated with twins or shear bands.

The complete set of data used in this study, which links microstructure with processing, is being made available on the Materials Commons database to serve as a foundation for Integrated Computational Materials Engineering model development to predict texture evolution in $\mathrm{Mg}$ alloys.

\section{ACKNOWLEDGMENTS}

This material is based upon work supported by the Department of Energy, Office of Energy Efficiency and Renewable Energy (EERE), under Cooperative Agreement Award Number DEEE007756 with the United States Council for Automotive Research's consortium The United States Automotive Materials Partnership (USAMP LLC). It was performed by University of Michigan under USAMP subaward during 2016-2020. We also gratefully acknowledge Professor Michelle Manuel of University of Florida who provided the cast plates.

\section{DATA AVAILABILITY}

The experimental data supporting this publication is available on the Materials Commons at http://doi.org/10.13011/m3-hvkb-rm86.

\section{CONFLICT OF INTEREST}

On behalf of all authors, the corresponding author states that there is no conflict of interest. 


\section{OPEN ACCESS}

This article is licensed under a Creative Commons Attribution 4.0 International License, which permits use, sharing, adaptation, distribution and reproduction in any medium or format, as long as you give appropriate credit to the original author(s) and the source, provide a link to the Creative Commons licence, and indicate if changes were made. The images or other third party material in this article are included in the article's Creative Commons licence, unless indicated otherwise in a credit line to the material. If material is not included in the article's Creative Commons licence and your intended use is not permitted by statutory regulation or exceeds the permitted use, you will need to obtain permission directly from the copyright holder. To view a copy of this licence, visit $h$ ttp://creativecommons.org/licenses/by/4.0/.

\section{REFERENCES}

1. A. Imandoust, C.D. Barrett, T. Al-samman, K.A. Inal, and H. El Kadiri, J. Mater. Sci. 52, 1. (2017).

2. N. Stanford, D. Atwell, A.G. Beer, C. Davies, and M.R. Barnett, Scr. Mater. 59, 772. (2008).

3. J.P. Hadorn, K. Hantzsche, S.B. Yi, J. Bohlen, D. Letzig, J.A. Wollmershauser, and S.R. Agnew, Metall. Mater. Trans. A 43, 1347. (2012).

4. D. Guan, X. Liu, J. Gao, L. Ma, B.P. Wynne, and W.M. Rainforth, Sci. Rep. 9, 7152. (2019).

5. D. Griffiths, D. Griffiths, Mater. Sci. Technol. 31, 10. (2015).

6. Y. Chino, T. Ueda, Y. Otomatsu, K. Sassa, X. Huang, K. Suzuki, and M. Mabuchi, Mater. Trans. 52, 1477. (2011).

7. B.C. Suh, J.H. Kim, J.H. Bae, J.H. Hwang, M.S. Shim, and N.J. Kim, Acta Mater. 124, 268. (2017).

8. D.W. Kim, B.C. Suh, M.S. Shim, J.H. Bae, D.H. Kim, and N.J. Kim, Metall. Mater. Trans. A 44, 2950. (2013).

9. J.Y. Lee, Y.S. Yun, B.C. Suh, N.J. Kim, W.T. Kim, and D.H. Kim, J. Alloys Compd. 589, 240. (2014).

10. J. Luo, H. Yan, N. Zheng, and R.S. Chen, Acta Metall. Sin. 29, 205. (2016).

11. J. Bohlen, J. Wendt, M. Nienaber, K.U. Kainer, L. Stutz, and D. Letzig, Mater. Charact. 101, 144. (2015).

12. T.D. Berman, and J.E. Allison, MagnesiumTechnology (Springer, Cham, 2020), pp 175-180.

13. A. Imandoust, C.D. Barrett, T. Al-Samman, M.A. Tschopp, E. Essadiqi, N. Hort, and H. El Kadiri, Metall. Mater. Trans. A 49, 1809. (2018).
14. J. Victoria-Hernández, S. Yi, D. Klaumünzer, and D. Letzig, Mater. Sci. Eng. A 761, 138054. (2019).

15. M.T. Pérez-Prado, J. Bohlen, S. Yi, D. Letzig, T. Al-Samman, J. Robson, M. Barnett, W. Poole, C. Mendis, S. Agnew, and N. Stanford, JOM 72, 2561. (2020).

16. S.R. Agnew, J.A. Horton, T.M. Lillo, and D.W. Brown, Scr. Mater. 50, 377. (2004).

17. L.W.F. Mackenzie, and M. Pekguleryuz, Scr. Mater. 59, 665. (2008).

18. F.J. Humphreys, and M. Hatherly, Recrystallization and Related Annealing Phenomena, 2nd edn. (Elsevier, Amsterdam, 2004)

19. A. Jäger, P. Lukác, V. Gartnerová, J. Haloda, and M. Dopita, Mater. Sci. Eng. A 432, 20. (2006).

20. R.K. Nadella, I. Samajdar, and G. Gottstein, in: Magnesium Proceedings of the 6th International Conference on Magnesium Alloys their Appl., 2005, pp. 1052-1057.

21. G. Gottstein, and T. Al Samman, Mater. Sci. Forum. 495497, 623-632. (2005).

22. D. Griffiths, B. Davis, and J.D. Robson, Metall. Mater. Trans. A 49, 321. (2018).

23. A.A. Luo, R. Shi, J. Miao, and T. Avey, JOM (2021). https://d oi.org/10.1007/s11837-021-04616-y.

24. F. Bachmann, R. Hielscher, and H. Schaeben, Solid State Phenom. 160, 63. (2010).

25. C.H. Cáceres, and A. Blake, Phys. Status Solidi 194, 147. (2002).

26. S. Abaspour, V. Zambelli, M. Dargusch, and C.H. Cáceres, Mater. Sci. Eng. A 673, 114. (2016).

27. T.D. Berman, T.M. Pollock, and J.W. Jones, Metall. Mater. Trans. A 47, 3125. (2016).

28. A.D. Murphy, and J.E. Allison, Metall. Mater. Trans. A Phys. Metall. Mater. Sci. 49, 1492. (2018).

29. J. Bohlen, M.R. Nurnberg, J.W. Senn, D. Letzig, and S.R. Agnew, Acta Mater. 55, 2101. (2007).

30. J.Y. Lee, Y.S. Yun, W.T. Kim, and D.H. Kim, Met. Mater. Int. 20, 885. (2014).

31. C. Ha, J. Bohlen, S. Yi, X. Zhou, H.G. Brokmeier, N. Schell, D. Letzig, and K.U. Kainer, Mater. Sci. Eng. A 761, 138053. (2019).

32. Z.R. Zeng, Y.M. Zhu, S.W. Xu, M.Z. Bian, C.H.J. Davies, N. Birbilis, and J.F. Nie, Acta Mater. 105, 479. (2016).

33. J.D. Robson, D.T. Henry, and B. Davis, Acta Mater. 57, 2739. (2009).

34. V.M. Miller, and T.M. Pollock, Metall. Mater. Trans. A 47, 1854. (2016).

Publisher's Note Springer Nature remains neutral with regard to jurisdictional claims in published maps and institutional affiliations. 